\title{
Application of Protein Phosphatase 1 Inhibition Assay and Reversed Phase Liquid Chromatography for the Detection of Microcystins in Algal Dietary Supplements
}

\author{
YI-MIN CHEN ${ }^{1,2}$, RANG HUANG² AND HONG-NONG CHOU ${ }^{1 *}$ \\ 1. Institute of Fisheries Science, National Taiwan University, 1, Sec. 4, Roosevelt Rd., Taipei 10617, Taiwan, R.O.C. \\ 2. Institute of Oceanography, National Taiwan University, Taipei 10617, Taiwan, R.O.C.
}

(Received: August 6, 2004; Accepted: November 25, 2004)

\begin{abstract}
Protein phosphatase 1 inhibition assay and reversed phase high performance liquid chromatography were adjusted for the detection of microcystins in Chlorella and Spirulina dietary supplements. Various sample preparation procedures for the enzyme and chemical assays were tested by the toxin-spiked samples to improve the sensitivity and accuracy of these methods. A silica gel solid phase extraction coupled with a deactivated elution had remarkably reduced the matrix interference from sample extracts and improved the detection of microcystins in both assays. High performance liquid chromatography could give the composition of different microcystins in the sample if the resolution of separation and toxin standards were available. On the contrary, protein phosphatase 1 inhibition assay gave an accumulated inhibition activity of the sample that could be converted to MCYST-LR equivalent according to the $\mathrm{IC}_{50}$ of this standard. A good sensitivity of $50 \mathrm{ppb}$ of microcystin in dried algal samples, was reached using the methods established in this research. Both enzyme and chemical assays were applied for the detection of possible microcystin contamination in the commercial products of algal dietary supplement. It was found that all nine samples of algal product examined in this study were free from microcystins.
\end{abstract}

Key words: solid-phase extraction (SPE), microcystins, protein phosphatase 1 inhibition assay, high performance liquid chromatography (HPLC)

\section{INTRODUCTION}

Microcystins (MCYSTs) are a group of cyclic heptapeptide toxins produced by freshwater blue-green algae (cyanobacteria), including species of Microcystis ${ }^{(1)}$, Anabaena $^{(2,3)}$, Nostoc $^{(4)}$ Oscillatoria agardhii ${ }^{(5,6)}$, and Planktothrix rubescens ${ }^{(7)}$. They are potent hepatotoxins against mammals, birds and fishes and cause immediate death from liver dysfunction and hemorrhage or a chronic effect of tumor promoting ${ }^{(8-10)}$. Human illness resulting from exposure to microcystins, though less common than poisoning of wild and domestic animals, has been reported $^{(11,12)}$. Toxicity of microcystins is generally regarded as a function of inhibitions on the activities of protein phosphatases 1 (PP-1) and 2A (PP-2A), the two major serine/threonine protein phosphatase in eukaryotes $(13,14)$

Microcystin contamination from toxic blue-green algal blooms in surface waters has attracted worldwide attentions for its potential health concern. The World Health Organization (WHO) thus developed a regulatory standard of $1.0 \mathrm{ppb}$ MCYST-LR equivalent of microcystins in drinking water, and a tolerant daily intake (TDI) of $0.04 \mu \mathrm{g}$ $\mathrm{day}^{-1} \mathrm{~kg}^{-1(15,16)}$. There are also concerns on the possible contamination of toxic blue-greens in the microalgal

\footnotetext{
* Author for correspondence. Tel: +886-2-33662879;

Fax: +886-2-23629919; E-mail: unijohn@ntu.edu.tw
}

cultures for dietary supplements or in natural waters where the commercial microalgae are harvested. Due to Microcystis contamination in Upper Klamath Lake (south Oregon) where the commercial blue-green dietary supplement products, Aphanizomenon flos-aquae, were harvested, the Oregon Health Division and the Oregon Department of Agriculture established a regulatory limit of $1.0 \mu \mathrm{g} / \mathrm{g}$ for microcystins in blue-green algae-containing products. Risk assessment data showed that a rather high proportion (85/87) of such products from Upper Klamath Lake were contaminated by MCYST-LR, with 63 samples (72\%) containing concentration higher than the official limit ${ }^{(17)}$. The fear of the possible microcystin contamination in bluegreen algal dietary supplements has extended to other microalgal sources, such as Chlorella and Spirulina products. In many areas of the world, manufacturers of microalgal products are often required to label the level of microcystin contaminants by the consumers (i.e. personal communications with microalgae factories).

High performance liquid chromatography (HPLC), mono- or poly-cloned immunoassay, protein phosphatase inhibition assay, and animal toxicity assay for the microcystin contents or toxicities have been developed. There are advantage and disadvantage of these methods for the microcystin analysis in surface waters for drinking or recreation, and in microalgal extracts. Generally a pre-cleaning process is needed to reduce the matrix interference in 
microalgal extracts, while a pre-concentrating process is applied for the low microcystin content in water samples. In the past decade, we were able to isolate various microcystins from the local isolates of Microcystis species (Figure 1), and to develop methods for toxin analysis using these microcystins and cultures in $1 a b^{(20-23)}$. Although the immunological method of ELISA has been reported to have the lowest detection limit of 20 ppb or less ${ }^{(24)}$, it could not differentiate the various immuno-cross reactivities of different toxins or distinguish these toxins in a mix ${ }^{(25)}$. Our previous studies indicated that protein phosphatase inhibition by microcystins might be corresponded to the mouse toxicity ${ }^{(23)}$ and an HPLC with a proper sample preparation was sensitive enough and highly reproducible in the microcystin analysis ${ }^{(24-25)}$. It is also noted that a newly proposed ISO20179 method, using HPLC and UV detection for the microcystin analysis in drinking and surface waters is currently employed in an inter-calibration practice (Luckas, personal communication).

In this study we developed a solid-phase-extraction (SPE) sample preparation in conjunction with a modified protein phosphatase inhibition assay and an HPLC system for the quantitative analysis of microcystins in Chlorella and Spirulina food supplementary products. Sensitivity and accuracy of various SPE procedures were compared to optimize the sample preparation in the developed system.

\section{MATERIALS AND METHODS}

\section{Protein Phosphatase 1 Inhibition Assay}

Protein phosphatase 1 (PP-1) inhibition assay using Escherichia coli recombinant protein phosphatase $1 \alpha$ isoform of rabbit muscle (Cat. No. 539493, Calbiochem, San Diego, CA, USA) in a buffer solution containing 50 $\mathrm{mM}$ Tris- $\mathrm{HCl}$ at $\mathrm{pH} 7.0,0.1 \mathrm{mM}$ EDTA, $5 \mathrm{mM}$ dithiothreitol, $0.2 \mathrm{mM} \mathrm{MnCl}_{2}$ and BSA of $0.2 \mathrm{mg} / \mathrm{mL}$, was adopted following the protocol of Dr. En-Yuh Chang (Technical Service, Calbiochem). The assay used $p$-nitrophenyl phosphate ( $p$-NPP) as substrate and the reaction product $p$-NP was detected at $405 \mathrm{~nm}$ using Spectra Fluor Plus microplate reader (Tecan AG, Hombrechtikon, Switzerland). The activity unit was defined as the phosphatase activity that hydrolyzed $p$-NPP to form $1 \mathrm{nmol} p$-NP $\mathrm{min}^{-1}$.

Standardization of enzyme reaction used the experimental solutions prepared as followed. Concentrations of MCYST-LR corresponding to 25.6, 12.8, 6.4, 3.2, 1.6, 0.8, 0.4 , and $0.2 \mathrm{ng}$ in $30 \mu \mathrm{L}$ methanol were prepared for calibration measurement. Enzyme solution was prepared by mixing $1.0 \mu \mathrm{L}$ of PP-1 (2500 unit/mL) in $2.5 \mathrm{~mL}$ buffer, while the substrate solution was prepared by dissolving 250 $\mathrm{mM} p$-NPP in the same buffer. Different concentration of authentic MCYST-LR, control (zero concentration of microcystin) and various algal extracts in $30 \mu \mathrm{L}$ of methanol were mixed with $970 \mu \mathrm{L}$ of buffer to make the sample solutions.

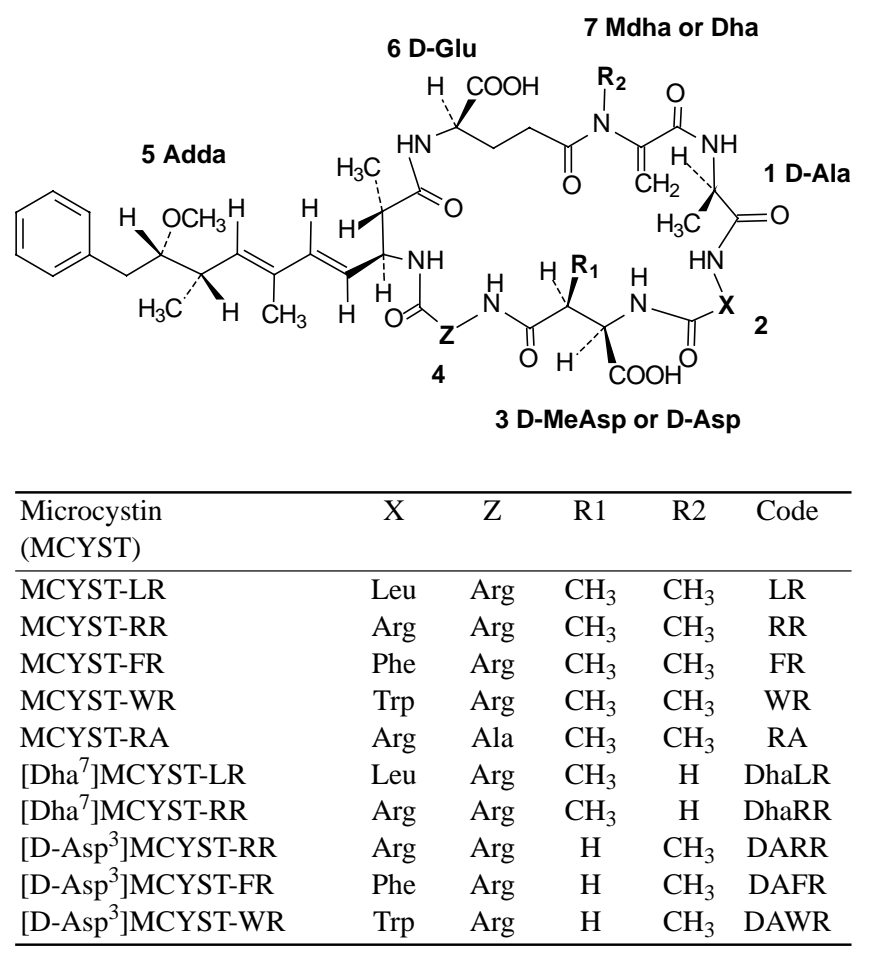

Figure 1. Structure of ten microcystins used as standards in this research.

(Mdha, methyldehydroalanine; MeAsp, methylaspartic acid; Adda, 3amino-9-methoxy-2,6,8-trimethyl-10-deca-4,6-dienoic acid; Leu, leucine; Arg, arginine; Phe, phenylalanine; Trp, tryptophane.)

Enzyme reactions were carried out in 96-well microplates for $1 \mathrm{hr}$ at $30^{\circ} \mathrm{C}$ before the absorption measurement by a microplate reader. The assay included three groups, the sample, control and blank, and each treatment had three replicates. In each well, $100 \mu \mathrm{L}$ of buffer, $50 \mu \mathrm{L}$ of sample solution and $50 \mu \mathrm{L}$ of enzyme solution were preincubated for certain period before the addition of $50 \mu \mathrm{L}$ of substrate solution, while the blank group used another 50 $\mu \mathrm{L}$ of buffer in replace of the enzyme solution. In the optimization study of PP-1 assay, pre-incubation time of 2 and 10 min were tested. The inhibitory activities of toxin standards and testing samples were determined by the activity ratio of sample to control, and expressed as percentage $(\%)$ activity of sample against control according to the following equations. The absorbance increase represented the difference of absorbance at $405 \mathrm{~nm}$ after $1 \mathrm{hr}$ of PP-1 enzyme reaction at $30^{\circ} \mathrm{C}$.

1. Activity of control $=$ (average absorbance increase of control) - (average absorbance increase of blank)

2. Activity of sample $=($ absorbance increase of sample $)$ - (average absorbance increase of blank)

3. Percentage activity $=(2) /(1) \times 100 \%$

The correlation curves plotted on the percentage activity to the concentration of toxin of 2 and $10 \mathrm{~min}$ preincubation time were compared and the concentration 
required to inhibit $50 \%$ enzyme activity of that in control $\left(\mathrm{IC}_{50}\right)$ of these samples was also calculated.

\section{High Performance Liquid Chromatography}

An isocratic HPLC equipped with UV absorption at $238 \mathrm{~nm}$ was used for the analysis of microcystins. A Luna phenyl-hexyl $5 \mu \mathrm{m}$ column $(4.6 \times 250 \mathrm{~mm}$, Phenomenex, Torrance, CA, USA) and a mobile phase of $0.01 \mathrm{M}$ ammonium acetate/acetonitrile $(73 / 27$ or $75 / 25$, v/v) at a flow rate of $1.0 \mathrm{~mL} \mathrm{~min}{ }^{-1}$ were applied. Authentic microcystins including MCYST-LR, MCYST-RR, MCYST-FR, MCYST-WR, MCYST-RA, [D-Asp ${ }^{3}$ ]MCYST-FR, and [D$\mathrm{Asp}^{3}$ ]MCYST-WR that were previously prepared in our earlier work ${ }^{(18)}$ were mixed to serve as the standard. The content of microcystins in each examined sample was determined based on the calibration curve of MCYST-LR within the range of 1- $900 \mathrm{ng}$.

\section{Analysis of Microcystins in Microalgal Dietary Supplements}

Both HPLC and PP-1 inhibition assay were applied for the determination of possible microcystin contamination in microalgal dietary supplements. Nine samples of Chlorella or Spirulina dietary supplement products (Table 1) purchased from local health food stores were studied in this experiment. Three to four algal tablets were randomly taken from each product package and then grinded to powder before extraction. To improve the detection, both normal and reversed phase SPE were applied in the PP-1 assay and compared for their removal of non-microcystin matrix interference, while normal phase (Si) SPE was applied for sample preparation in HPLC analyses. Microcystin recovery was also determined for the normal phase SPE in PP-1 inhibition assay using toxin-spiked microalgal products.

\section{(I) Sample preparation for HPLC}

One hundred milligrams of each microalgal sample powder was extracted vigorously with $10 \mathrm{~mL}$ of methanol twice. Clear solution of both methanol extracts were collected by centrifugation and then dried with a rotary evaporator. Before HPLC analysis of microcystins in these

Table 1. Microalgal dietary supplement products in study

\begin{tabular}{ll}
\hline \multicolumn{1}{c}{ Product } & Code \\
\hline Spichlo Chlorella Tablet & FE-C \\
Green Shine Chlorella Tablet & VD-C \\
Green Gem Chlorella & TC-C \\
Hou Lu Mei Chlorella Tablet & GB-C \\
Arkea Chlorella Tablet & AK-C \\
Green Shine Spirulina & VD-S \\
Grren Gem Spirulina & TC-S \\
Arkea Spirulina Capsule & AK-S \\
Spailen Spirulina & NP-S \\
\hline
\end{tabular}

samples, they were treated by an SPE cleaning process. The SPE used a $0.6 \mathrm{~cm}$ i.d. column of $0.1 \mathrm{~g}$ silica gel (Baker silica gel $40 \mu \mathrm{L}$ flash chromatography packing, J. T. Baker, Phillipsburg, NJ, USA) which was pre-conditioned with $5 \mathrm{~mL}$ of ethyl acetate/isopropanol (4/3, v/v) before sample loading. Sample extracts were top-loaded on the SPE column in $0.5 \mathrm{~mL}$ of conditioning solution. They were first washed by $1.0 \mathrm{~mL}$ of the same solution and then eluted by $1.0 \mathrm{~mL}$ of methanol. The methanol effluent was dried and re-dissolved in $50 \mu \mathrm{L}$ of methanol, of which $10 \mu \mathrm{L}$ was analyzed by HPLC.

\section{(II) Sample preparation for PP-1 inhibition assay}

A solution of $5 \%$ acetic acid ${ }^{(26)}$ was used for microalgal extraction and the extracts were subject for both normal and reversed phase SPE treatment before PP-1 inhibition assay. A reversed phase SPE using a $0.6 \mathrm{~cm}$ i.d. column filled with $0.1 \mathrm{~g}$ Cosmosil 40C18-PREP gel ( $40 \mu \mathrm{m}$, Nacalai Tesque, Kyoto, Japan) was conditioned first with $1.0 \mathrm{~mL}$ of $90 \%$ methanol and then $1.0 \mathrm{~mL}$ of $5 \%$ acetic acid. Samples were top-loaded on the column and washed with $1.0 \mathrm{~mL}$ of $10 \%$ methanol before eluting with $1.0 \mathrm{~mL}$ of $90 \%$ methanol. The effluent were dried under $\mathrm{N}_{2}$ stream and then re-dissolved in $1.25 \mathrm{~mL}$ of methanol. Thirty microliter of the methanol solution was mixed with $970 \mu \mathrm{L}$ of buffer as sample solution and analyzed by the PP-1 inhibition assay as described above. Results of PP-1 inhibition assay after C18 SPE sample preparation were compared with the results after Si SPE treatment. The Si normal phase SPE, the same as the sample preparation method for HPLC, was applied for the methanol extracts in PP-1 inhibition assay.

Two microalgal products, VD-C and VD-S, which were proven free from microcystin contamination in the previous analysis, were spiked with $1.0 \mathrm{ppm}$ authentic MCYST-LR and subject for methanol extraction and Si SPE before PP-1 inhibition assay. Toxin contents obtained from PP-1 assay were compared between using and not using this Si SPE sample preparation.

\section{RESULTS}

\section{Optimization of PP-1 Inhibition Assay}

Activities of PP-1 decreased remarkably with the increase of MCYST-LR concentration (Figure 2) in the standardization of PP-1 inhibition assay using authentic MCYST-LR over the range of 5.12-0.04 ng/mL. It was also found that inhibition of phosphatase activity was enhanced when the pre-incubation of MCYST-LR and enzyme increased from $2 \mathrm{~min}$ to $10 \mathrm{~min}$, especially in the lower concentration of MCYST-LR (Figure 2B). Concentration of $50 \%$ inhibition $\left(\mathrm{IC}_{50}\right)$ of MCYST-LR on PP-1 activity was calculated as 0.1 and $0.5 \mathrm{ng} / \mathrm{mL}$ for the 2 and 10 min pre-incubation treatment, respectively (Figure 2 $\mathrm{A}$ and $\mathrm{B})$. 

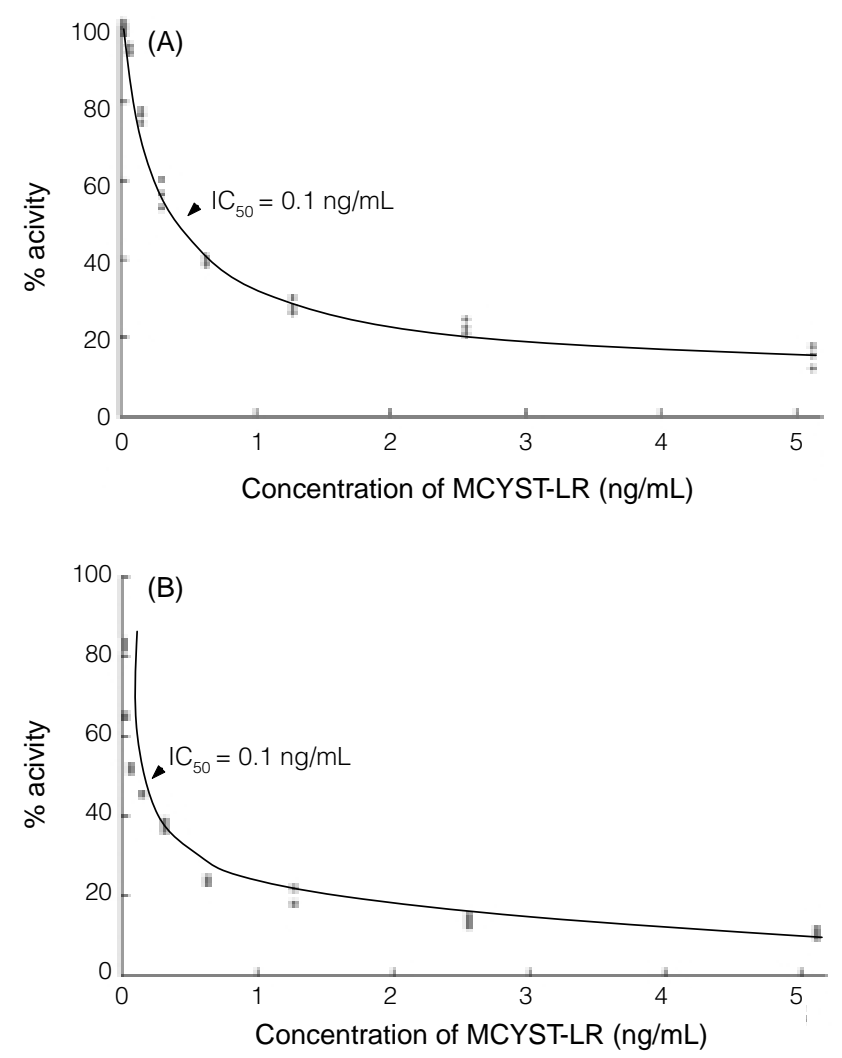

Figure 2. Inhibition of PP-1 activities by various amount of MCYSTLR which were pre-incubated with PP-1 for (A) $2 \mathrm{~min}$, and (B) for 10 min. $\mathrm{IC}_{50}$ representing the concentration of MCYST-LR which poses the $50 \%$ inhibition of PP-1 activity.

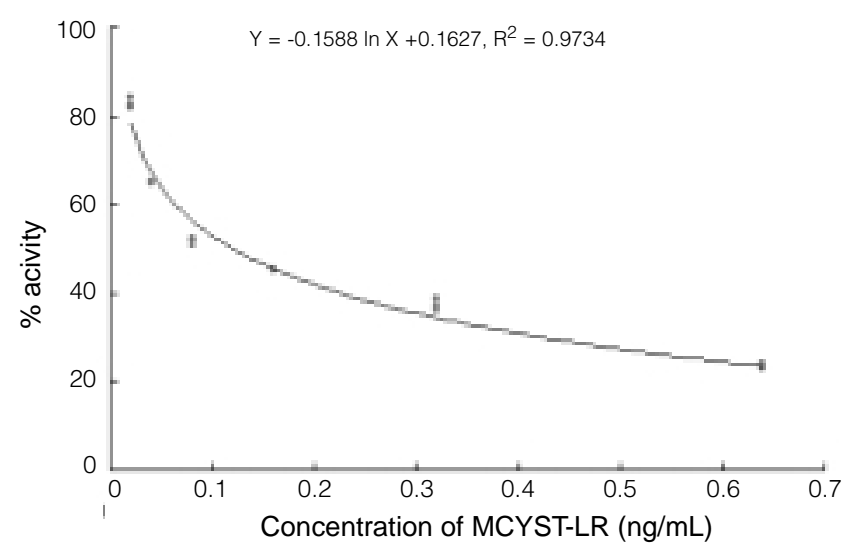

Figure 3. Regression of the inhibition of PP-1 activities by MCYSTLR at different concentrations from 0.02 to $0.64 \mathrm{ng} / \mathrm{mL}$, with a 10 min pre-incubation of enzyme and toxin.

A nonlinear regression curve based on the correlation of PP-1 activities and microcystin concentrations was revealed in Figure 3. A formula, $\mathrm{Y}=-0.1588 \ln \mathrm{X}+$ 0.1627 (where $\mathrm{Y}=\%$ activity of control, $\mathrm{X}=$ concentration of MCYST-LR, ng/mL), using the natural logarithm function that best fit the curve of the toxin standard over the range of $0.02-0.64 \mathrm{ng} / \mathrm{mL}\left(\mathrm{R}^{2}=0.9734\right)$ was then established accordingly. The equation was thus served as the calibration curve for quantitative determination of microcystin contamination in microalgal dietary supplements using PP-1 phosphatase inhibition assay. The least concentration of MCYST-LR, $0.02 \mathrm{ng} / \mathrm{mL}$ showed a PP-1 activity near $78 \%$ was determined as detection limit in PP-1 inhibition assay.

\section{Analysis of Microcystins in Microalgal Dietary Supplements}

\section{(I) by HPLC}

Standards of seven different microcystins were not well resolved by the reversed phase HPLC using a Luna phenyl-hexyl $5 \mu \mathrm{m}$ column and $0.01 \mathrm{~N}$ ammonium acetate/ acetonitrile (73/23) elution. However the resolution was much improved if the ratio of effluent composition was changed to $75 / 25$. It was also found the sample preparation procedure of Si SPE removed the unidentified interference peaks that might confuse the qualitative identification of known microcystins. No microcystin was detected in the nine microalgal dietary supplement products of Chlorella and Spirulina collected from local health stores. This observation suggested that the concentration of microcystins in microalgal products was lower than $50 \mathrm{ppb}$, as estimated by the HPLC detection limit $(\mathrm{S} / \mathrm{N} \geq 2)$ of $1.0 \mathrm{ng}$ for microcystin-LR and -RR at the sample size of $0.02 \mathrm{~g}$ dry algae.

\section{(II) By PP-1 Inhibition Assay}

Protein phosphatase 1 inhibition assays of various microalgal products are presented in Table 2. Data of MCYST-LR equivalent containing in each sample were converted from the \% activity and the calibration curve of standard. Two distinct sample preparations, including acetic acid $(5 \%)$ and methanol extract, combined with their respective reversed phase SPE and normal phase SPE treatment, were applied in these enzyme assays. The inhibition of PP-1 activity by methanol extracts that were followed by Si SPE treatment were not pronounced (97.2$104.0 \%$ of the control), comparing with those of acetic acid extract and C18 SPE treatment. It could be asserted that the content of microcystins presented as MCYST-LR equivalent in microalgal products were lower than $40 \mathrm{ppb}$, based on the detection limit of $0.02 \mathrm{ng} / \mathrm{mL}$ microcystin-LR and the sample size of $480 \mu \mathrm{g}$ dried algae $/ \mathrm{mL}$ in the enzyme assay. A lower enzyme activities (62.8-82.0\% of the control) in the samples of acetate extract showed C18 SPE sample clean-up procedure were not able to remove the interference components that reduced the absorbance at 405 nm. Converted MCYST-LR contents in these samples from $\mathrm{IC}_{50}$ of PP-1 assay did not agree with the results obtained from HPLC.

The effectiveness of $\mathrm{Si}$ normal phase SPE in improving the PP-1 inhibition assay on microalgal products was deduced from the toxin contents analyzed in the 
Table 2. Protein phosphatase 1 inhibition assays of microalgal products through two sample preparations of reversed and normal phase solidphase-extraction respectively. (Values presented are mean \pm standard deviation of 3 replications.)

\begin{tabular}{llcccc}
\hline Products & Code & \multicolumn{2}{c}{ Reversed phase $^{\mathrm{a}}$} & \multicolumn{2}{c}{ Normal phase $^{\mathrm{b}}$} \\
\hline Chlorella & & \% activity & $\begin{array}{c}\text { MCYST-LR } \\
\text { equivalent (ppb) }\end{array}$ & $\begin{array}{c}\text { \% activity } \\
\text { equivalent (ppb) }\end{array}$ \\
& FE-C & $68.4 \pm 0.8$ & $78.2 \pm 0.9$ & $98.5 \pm 1.0$ & $<40$ \\
& VD-C & $67.7 \pm 5.2$ & $81.7 \pm 6.3$ & $97.2 \pm 2.8$ & $<40$ \\
& TC-C & $66.9 \pm 1.8$ & $85.9 \pm 2.3$ & $99.1 \pm 3.3$ & $<40$ \\
Spirulina & GB-C & $71.3 \pm 2.0$ & $65.1 \pm 1.8$ & $98.1 \pm 6.5$ & $<40$ \\
& AK-C & $63.8 \pm 2.1$ & $104.4 \pm 3.4$ & $103.6 \pm 6.0$ & $<40$ \\
& VD-S & $82.0 \pm 7.2$ & $80.2 \pm 6.0$ & $102.6 \pm 2.7$ & $<40$ \\
& TC-S & $68.0 \pm 5.1$ & $90.9 \pm 2.7$ & $102.0 \pm 5.5$ & $<40$ \\
\hline
\end{tabular}

${ }^{\mathrm{a} A c e t i c}$ acid (5\%) extract of samples, treated with $\mathrm{C} 18$ solid-phase-extraction.

${ }^{\mathrm{b}}$ Methanol extract of samples, treated with Si solid-phase-extraction.

methanol extract before and after Si SPE sample preparation of MCYST-LR-spiked microalgal products. It was found the Si SPE treatment could recover almost $100 \%$ of the inhibition of PP-1 by MCYST-LR (Table 3).

\section{DISCUSSION}

Chronic exposures to low level microcystins in contaminated drinking water or microalgal dietary supplements may pose potential health risks to the general public. Thus a fast, sensitive, accurate, and convenient methodology is essential for the routine monitoring of microcystins in drinking water, dietary supplements and other food materials. Previous literatures have demonstrated that protein phosphatase inhibition assays, as well as HPLC methods provided precise and reproducible analyses of microcystins ${ }^{(14,24,25)}$. In this study we indicated a reversed phase HPLC coupled with a sample preparation of silica gel SPE is effective in the analysis of microcystin in microalgal dietary supplements. Detection limit of the method has been determined to reach as low as $50 \mathrm{ppb}$, the same level of sensitivity an ELISA method may reach ${ }^{(22)}$. High performance liquid chromatography has its advantages of lower cost per sample and quantitative determination of each microcystin while comparing with the ELISA immunoassay.

Similar Si SPE applied in HPLC analysis was also applied in PP-1 inhibition for the methanol extract of microalgal products and was proven an efficient sample preparation operation in this study. It removed the constituents that interfered with the detection of PP-1 reaction product. Previous studies indicated that methanol extract of non-toxic Microcystis ${ }^{(19)}$ and mussel ${ }^{(25)}$ gave higher signal of PP-1 reaction product. Such matrix effect was speculated from indigenous phosphatases ${ }^{(25)}$ or salts (M. Quilliam, personal communication) in the assayed samples. In the present study, interferences caused by salts and indigenous phosphatase were unlikely to happen, since methanol was used for sample extraction. On the contrary, acetic acid extract of algal supplement caused nonspecific inhibition of
Table 3. Toxin contents before and after Si SPE sample preparation using PP-1 inhibition assay on MCYST-LR-spiked microalgal products. (Values presented are mean \pm standard deviation of 3 replications.)

\begin{tabular}{lcc}
\hline & \multicolumn{2}{c}{ Percentage of the spiked MCYST-LR analyzed } \\
\cline { 2 - 3 } Samples & Extract before SPE & Extract after SPE \\
\hline VD-C & $89.2 \pm 8.2$ & $101.9 \pm 9.4$ \\
VD-S & $92.4 \pm 3.6$ & $102.2 \pm 5.6$ \\
\hline
\end{tabular}

PP-1 activity even after treatment with C18 SPE. In addition, Si SPE showed a good recovery of microcystin in the toxin-spiked experiment. Our data in the HPLC analysis of Microcystis extracts showed the same high recovery using Si SPE sample preparation for HPLC, not only to MCYST-LR but also to other microcystins ${ }^{(19)}$. It was also evident by the MALDI-TOF analysis of the toxin profiles before and after this SPE treatment (unpublished data). Thus, the use of silica gel SPE is recommended in sample preparation following methanol extraction for the PP-1 inhibition assay of microalgal dietary supplements. Although a reversed phase SPE has been generally applied as a sample preparation for water sample in HPLC analysis, Si SPE sample preparation is more convenient in operation for the methanol extract of microalgal samples, since the nonpolar components that may interfere the following reversed phase HPLC analysis can be clarified by this normal phase SPE sample preparation.

Previous report showed that PP-1 inhibition assay method was not sensitive enough in the detection of microcystins at ppb level ${ }^{(22)}$. However, PP-1 inhibition assay can be improved by increasing the pre-incubation time of enzyme and MCYST-LR or sample extracts before the addition of enzyme substrate. In an earlier trial we premixed the sample extracts and substrate solution before the adding of enzyme solution, as a routine procedure for the okadaic acid analysis by PP-2A inhibition assay ${ }^{(28)}$, in which no time was allowed for the microcystin to counteract PP-1. The results showed poor reproducibility and poor sensitivity. Various premix time in a range of 2 to $10 \mathrm{~min}$ were applied for the interaction of toxin and enzyme solution appeared in papers using protein phosphatase inhi- 
bition assay for microcystin detection ${ }^{(29-33)}$. However, there was no comparison of these premix-time differences. In this study we found that 10 min pre-incubation was sufficient to have a fast and pronounced inhibition response in the PP-1 inhibition assay and a detection limit of 0.02 $\mathrm{ng} / \mathrm{mL}$ for MCYST-LR. It is equivalent to $40 \mathrm{ppb}$ of MCYST-LR in microalgal products, almost reach the sensitivity of the polyclone ELISA method ${ }^{(22)}$.

In conclusion, both PP-1 inhibition assay and HPLC reach the required sensitivity and precision for microcystin analysis in microalgal dietary supplements, if coupled with a silica gel solid-phase-extraction pre-cleaning. All the microalgal dietary supplement products analyzed in this study are practically free from microcystin contamination.

\section{ACKNOWLEDGEMENTS}

This work was partly supported by grants (NSC922311-B002-103, and NSC91-2323-B002-009 issued to $\mathrm{H}$. N. Chou) from National Science Council, Taiwan.

\section{REFERENCES}

1. Namikoshi, M., Rinehart, K. L., Sakai, R., Stotts, R. R., Dahlem, A. W. and Beasley, V. R. 1992. Identification of 12 hepatotoxins from a Homer Lake bloom of the cyanobacteria Microcystis aeruginosa, Microcystis viridis, and Microcystis wesenbergii: nine new microcystins. J. Org. Chem. 57: 866-872.

2. Namikoshi, M., Sivonen, K., Evans, W. R., Carmichael, W. W., Sun, F., Rouhiainen, L., Luukkainen, R. and Rinehart, K. L. 1992. Two new L-serine variants of microcystins-LR and -RR from Anabaena sp. strains 202A1 and 202A2. Toxicon 30: 1457-1464.

3. Sivonen, K., Namikoshi, M., Evans, W. R., Carmichael, W. W., Sun, F., Rouhiainen, L., Luukkainen, R. and Rinehart, K. L. 1992. Isolation and characterization of a variety of microcystins from seven strains of the cyanobacterial genus Anabaena. Appl. Environ. Microbiol. 58: 2495-2500.

4. Namikoshi, M., Rinehart, K. L., Sakai, R., Sivonen, K. and Carmichael, W. W. 1990. Structures of three new cyclic heptapeptide hepatotoxins produced by the cyanobacterium (blue-green alga) Nostoc sp. strain 152. J. Org. Chem. 55: 6135-6139.

5. Meriluoto, J. A. O., Sandstrom, A., Eriksson, J. E., Remaud, G., Craig, A. G. and Chattopadhyaya, J. 1989. Structure and toxicity of a peptide hepatotoxin from the cyanobacterium Oscillatoria agardhii. Toxicon 27: 1021-1034.

6. Luukkainen, R., Sivonen, K., Namikoshi, M., Fardig, M., Rinehart, K. L. and Niemela, S. I. 1993. Isolation and identification of eight microcystins from thirteen Oscillatoria agardhii strains and structure of a new microcystin. Appl. Environ. Microbiol. 59: 2204-2209.
7. Blom, J. F., Robinson, J. A. and Juttner, F. 2001. Higher grazer toxicity of [D-Asp3, (E)-Dhb7] microcystin-RR of Planktothrix rubescens as compared to different microcystins. Toxicon 39: 1923-1932.

8. Theiss, W. C., Carmichael, W. W., Wyman, J. and Bruner, R. 1988. Blood pressure and hepatocellular effects of the cyclic heptapeptide toxin produced by the freshwater cyanobacterium (blue-green alga) Microcystis aeruginosa strain PCC-7820. Toxicon 26: 603-613.

9. Matsushima, R. N., Ohta, T., Nishiwaki-Suganuma, M., Kohyama, K., Ishikawa, T., Carmichael, W. W. and Fujiki, H. 1992. Liver tumor promotion by the cyanobacterial cyclic peptide toxin microcystin-LR. J. Cancer Res. Clin. Oncol. 116: 609-614.

10. Kaya, K. 1996. Toxicology of microcystins. In "Toxic Microcystis". pp. 175-202. Watanabe, M. F., Harada, K. I., Carmichael, W. W. and Fujiki, H. eds. CRC Press. New York, U. S. A.

11. Falconer, I. R., Beresford, A. M. and Runnegar, M. T. C. 1983. Evidence of liver damage by toxin from a bloom of the blue-green alga, Microcystis aeruginosa. Med. J. Aust. 1: 511-514.

12. Jochimsen, E. M., Carmichael, W. W., An, J. S., Cardo, D. M., Cookson, S. T., Holmes, C. E., Antunes, M. B., de Melo Filho, D. A., Lyra, T. M., Barreto, V. S., Azevedo, S. M. and Jarvis, W. R. 1998. Liver failure and death after exposure to microcystins at a hemodialysis center in Brazil. N. Engl. J. Med. 338: 873-878.

13. Mackintosh, C., Beattie, K. A., Klumpp, C., Cohen, C. and Codd, G. A. 1990. Cyanobacterial microcystin-LR is a potent and specific inhibitor of protein phosphatase 1 and $2 \mathrm{~A}$ from both animals and higher plants. FEBS Lett. 264: 187-192.

14. Toivola, D. M. and Eriksson, J. E. 1990. Toxins affecting cell signaling and alternation of cytoskeletal structure. Toxicol. in Vitro 13: 521-530.

15. WHO. 1997. Report of the Working Group on Chemical Substances in Drinking Water, Section 5-2 MicrocystinLR. WHO. Geneva, Switzerland.

16. Hitzfeld, B. C., Hoger, J. and Dietrich, D. R. 2000. Cyanobacterial toxins: removal during drinking water treatment, and human risk assessment. Environ. Toxicol. 108: 113-121.

17. Gilroy, D. J., Kauffman, K. W., Hall, R. A., Huang, X. and Chu, F. S. 2000. Assessing potential health risks from microcystin toxins in blue-green algae dietary supplements. Environ. Health Perspec. 108: 435-439.

18. Lee, T. H. Chen, Y. M. and Chou, H. N. 1998. First report of microcystins in Taiwan. Toxicon 36: 247-255.

19. Lee, T. H., Chen, Y. M. and Chou, H. N. 1999. Toxicity assay of cyanobacterial strains using Artemia salina in comparison with the mouse bioassay. Acta Zoologica Taiwanica 10: 1-9.

20. Lee, T. H. and Chou, H. N. 2000. Isolation and identification of seven microcystins from a cultured M. TN-2 strain of Microcystis aeruginosa. Bot. Bull. Academia 
Sinica 41: 1987-2002.

21. Chen, Y. M., Lee, T. H., Huang, R., Bai, J. Y. and Chou, H. N. 2004. Comparison of protein phosphatase inhibition assay with the mouse and Artemia toxicity assays in the toxic Microcystis screening. Aquat. Toxicol. (submitted).

22. Yu, F. Y., Liu, B. H., Chou, H. N. and Chu, F. S. 2002. Development of a sensitive ELISA for the determination of microcystins in algae. J. Agri. Food Chem. 50: 4176-4182.

23. Metcalf, J. S., Beattie, K. A., Pflugmacher, S. and Codd, G. A. 2000. Immuno-crossreactivity and toxicity assessment of conjugation products of the cyanobacterial toxin, microcystin-LR. FEBS Microbiol. Lett. 189: 151-158.

24. de Magalhaes, V. F., Soares, R. M. and Azevedo, S. M. F. O. 2001. Microcystin contamination in fish from the Jacarepagua Lagoon (Rio de Janeiro, Brazel): ecological implication and human health risk. Toxicon 39: 1077-1085.

25. Pyo, D. and Shin, H. 2002. Extraction and analysis of microcystin $R R$ and $L R$ in cyanobacteria using a cyano cartridge. J. Biochem. Biophys. Methods 51: 103-109.

26. Watanabe, M. F., Oishi, S., Harada, K. I., Matsuura, K., Kawai, H. and Suzuki, M. 1988. Toxins contained in Microcystis species of cyanobacteria (blue-green algae). Toxicon 26: 1017-1025.

27. Honkanen, R. E., Stapleton, J. D., Bryan, D. E. and Abercrombie, J. 1996. Development of a protein phosphatase-based assay for the detection of phosphatase inhibitors in crude whole cell and animal extracts. Toxicon 34: 1385-1392.
28. Tubaro, A., Florio, C., Luxich, E., Sosa, S., Loggia, R. D. and Yasumoto, T. 1996. A protein phosphatase 2A inhibition assay for a fast and sensitive assessment of akadaic acid contamination in mussels. Toxicon 34: 743-752.

29. Fontal, O. I., Vieytes, M. R., Baptista de Sousa, J. M. V., Louzao, M. C. and Botana, L. M. 1999. A fluorescent microplate assay for microcystin-LR. Anal. Biochem. 269: 289-296.

30. Rivasseau, C., Racaud, P., Deguin, A. and Hennion, M. C. 1999. Development of a bioanalytical phosphatase inhibition test for the monitoring of microcystins in environmental water samples. Analytica Chimica Acta 394: 243-257.

31. Wong, B. S. F., Lam, P. K. S., Xu, L., Zhang, Y. and Richardson, B. J. A. 1999. Colorimetric assay for screening microcystin class compounds in aquatic systems. Chemosphere 38: 1113-1122.

32. Xu, L. H., Lam, P. K. S., Chen, J. P., Xu, J. M., Wong, B. S. F., Zhang, Y. Y., Wu, R. S. S. and Harada, K. I. 2000. Use of protein phosphatase inhibition assay to detect microcystins in Donghu Lake and a fishpond in China. Chemosphere 41: 53-58.

33. Heresztyn, T. and Nicholson, B. C. 2001. Determination of cyanobacterial hepatotoxins directly in water using a protein phosphatase inhibition assay. Wat. Res. 35: 3049-3056. 